\title{
ACS APPLIED NANO MATERIALS
}

Subscriber access provided by University of Winnipeg Library

\section{Article}

\section{Intermetallic CoFeln Heusler Alloy Nanowires for Spintronics Applications}

Ladislav Galdun, Victor Vega, Zuzana Vargova, Enrique D.

Barriga-Castro, Carlos Luna, Rastislav Varga, and Victor M. Prida

ACS Appl. Nano Mater., Just Accepted Manuscript • Publication Date (Web): 27 Nov 2018

Downloaded from http://pubs.acs.org on November 27, 2018

\section{Just Accepted}

"Just Accepted" manuscripts have been peer-reviewed and accepted for publication. They are posted online prior to technical editing, formatting for publication and author proofing. The American Chemical Society provides "Just Accepted" as a service to the research community to expedite the dissemination of scientific material as soon as possible after acceptance. "Just Accepted" manuscripts appear in full in PDF format accompanied by an HTML abstract. "Just Accepted" manuscripts have been fully peer reviewed, but should not be considered the official version of record. They are citable by the Digital Object Identifier (DOI@). "Just Accepted" is an optional service offered to authors. Therefore, the "Just Accepted" Web site may not include all articles that will be published in the journal. After a manuscript is technically edited and formatted, it will be removed from the "Just Accepted" Web site and published as an ASAP article. Note that technical editing may introduce minor changes to the manuscript text and/or graphics which could affect content, and all legal disclaimers and ethical guidelines that apply to the journal pertain. ACS cannot be held responsible for errors or consequences arising from the use of information contained in these "Just Accepted" manuscripts. 


\title{
Intermetallic $\mathrm{Co}_{2} \mathrm{FeIn}$ Heusler Alloy Nanowires
}

\section{for Spintronics Applications}

\author{
Ladislav Galdun ${ }^{1,2}$, Victor Vega ${ }^{2}$, Zuzana Vargová ${ }^{1}$,Enrique D. Barriga-Castro ${ }^{3}$, Carlos Luna ${ }^{4}$, \\ Rastislav Varga ${ }^{1}$, Victor M. Prida, ${ }^{2, *}$ \\ ${ }^{1}$ CPM-TIP, UPJS, Park Angelinum 9, 04154 Kosice, Slovakia. \\ ${ }^{2}$ Departamento de Física, Facultad de Ciencias, Universidad de Oviedo, C/ Federico Garcia \\ Lorca $\mathrm{n}^{\circ}$ 18, 33007-Oviedo, Asturias, Spain \\ ${ }^{3}$ Centro de Investigación en Química Aplicada (CIQA), Blvd. Enrique Reyna Hermosillo No. \\ 140, Saltillo, 25294 Coahuila, Mexico \\ ${ }^{4}$ Universidad Autónoma de Nuevo León (UANL), Av. Universidad S/N, San Nicolás de los \\ Garza, Nuevo León 66455, Mexico \\ *E-mail: vmpp@uniovi.es
}

KEYWORDS: nanoporous alumina templates, electrodeposited nanowires, Heusler alloy, magnetic anisotropy, spintronics. 


\begin{abstract}
Cylindrical $\mathrm{Co}_{2} \mathrm{FeIn}$ Heusler alloy nanowires are synthesized via template-assisted electrochemical deposition into the hexagonally self-ordered nanopores of hard-anodic alumina membranes. The electroplated nanowires, with $180 \pm 20 \mathrm{~nm}$ in diameter and around $14.5 \mu \mathrm{m}$ in length, exhibit a polycrystalline nature and they are homogenous in composition. High-resolution transmission electron microscopy (HR-TEM), selected area electron diffraction (SAED) and Xray diffraction (XRD) analysis confirmed a cubic $A 2$ disordered phase of the ferromagnetic Heusler compound, with a lattice parameter of $a=5.764 \pm 0.001 \AA$. In addition, these structural characterizations reveal that the $\mathrm{Co}_{2} \mathrm{FeIn}$ nanowires display a polycrystalline structure with a pronounced $\{220\}$ texture. The temperature dependent magnetization behavior and anisotropy field distribution calculations display a dominant role of shape, magnetocrystalline and magnetoelastic terms on the effective magnetic anisotropy of $\mathrm{Co}_{2} \mathrm{FeIn}$ alloyed nanowire arrays. Magneto-optical Kerr effect measurements performed on single freestanding nanowires, after releasing from the hosting alumina templates, confirmed competing behavior between shape and magnetocrystalline anisotropy contributions, which lead to complex magnetization reversal process. This fabrication technique offers a promising and new forward-looking synthesis of novel Heusler nanomaterials for spintronics applications.
\end{abstract}




\section{Introduction}

Nowadays there is an increasing interest for searching novel magnetic nano-materials with a high spin polarization at the Fermi energy, which are interesting for spintronics applications in magnetic data storage, like magnetic hard discs and random access memories (MRAMs), or magnetic domain wall race-track memory devices [1-4].

Heusler alloys are well-known suitable candidates for many applications, due to their tunable electronic structure, which influences their peculiar physical properties ranging from superconductivity [5], through semiconductivity [6], even to half-metallic ferromagnetism [7]. Half-metallicity is characterized by a metallic behavior in the majority spin channel and a semiconducting behavior with a gap at the Fermi level in the minority spin channel, which provides a $100 \%$ spin polarization [8]. Therefore, the half-metallic character of some Heusler alloys have attracted great interest due to their potential application as a highly spin-polarized current source in the research fields of thermoelectric [9], and spintronic devices [10-13].

Heusler alloys are ternary compounds with chemical formula $\mathrm{X}_{2} \mathrm{YZ}$ showing various structures ranging from ordered $L 2{ }_{1}$, moderately ordered $B 2$ (Y-Z disorder), to completely disordered $A 2$ (XY-Z disorder) structural types. The $\mathrm{X}$ and $\mathrm{Y}$ atoms are usually selected from either transition or rare-earth metals, while the $\mathrm{Z}$ sub-lattice is represented by p-block element [8]. Heusler alloys are usually prepared as single or polycrystalline bulk materials or thin films [14-16]. Currently this fascinating group of materials faces a new challenge because of the downsizing to the nanoscale regime for numerous potential applications such as in spintronics, topological insulators and magnetic skyrmions [17]. 
The research on nanostructures is strongly motivated by the observation that points to the fact that the bulk material properties can abruptly change by scaling the material size down to the nanoscale dimension $[18,19]$. This approach may enhance the typical properties of Heusler alloys usually exhibited in the form of bulk and offers the opportunity to incorporate these novel nanoscale materials into the products of industrial technologies, such as in data storage and thermoelectric cooling devices, among many other applications [20-24].

The large interest on the fabrication of metallic and magnetic nanowires for many kinds of applications resulted in the revelation of novel binary or ternary Co-based alloy nanowires, such as $\mathrm{Co}-\mathrm{Ni}$ [25-27], or $\mathrm{Co}-\mathrm{Cu}$ [28, 29], $\mathrm{Co}-\mathrm{Fe}-\mathrm{Ni}$ [30] and $\mathrm{Co}-\mathrm{Fe}-\mathrm{Cu}$ [31] prepared by electrochemical deposition into the self-ordered nanopores of the anodic aluminum oxide (AAO) membranes. The peculiar one-dimensional (1D) geometry of the electrodeposited ferromagnetic nanowires has been recently reported to exhibit novel structural and physic-chemical features [3235].

$\mathrm{Co}_{2}$-based Heusler alloys have a peculiar role in the potential applications of spintronics based on their theoretically predicted half-metallic nature at the Fermi energy (100\% spin polarization), high Curie temperature and small Gilbert damping [36]. However, up to now there are only few reports in the literature dealing with ternary intermetallic Co-based Heusler alloys nanowires: such as single crystal nanowires made of CoSiGe alloys grown by spontaneous chemical vapor transport displaying orthorhombic $\mathrm{Co}_{2} \mathrm{Si}$ structure [37]; $\mathrm{Co}_{2} \mathrm{Fe} A l$ prepared by electrospinning with a wide range of thickness from 50 to $500 \mathrm{~nm}$ and having $B 2$ or $A 2$ disordered crystalline structure [38]; polycrystalline fcc CoNiGa nanowires array potentiostatically electrodeposited into AAO templates [39]; electron-beam evaporated $\mathrm{CoFeAl}$ nanowires exhibiting highly efficient spin current induced by thermal-gradient spin injection [40]; $\mathrm{Co}_{2} \mathrm{FeGa}$ nanowires prepared by silica 
template assisted method exhibiting a highly ordered $L 2{ }_{1}$ crystalline structure, and with an additional nonmagnetic $\mathrm{Co}_{\mathrm{x}} \mathrm{Fe}_{3-\mathrm{x}} \mathrm{O}_{4}$ surface layer of about $10 \mathrm{~nm}$ [41]; half-metal $\mathrm{CoH}_{3}$ 1D molecular nanowires exhibiting ferromagnetic ground state induced by carrier doping with a theoretically predicted $100 \%$ spin-polarized current [42]; and more recently, $\mathrm{Fe}_{2} \mathrm{CoSn}$ [43] and $\mathrm{Co}_{2} \mathrm{Mn}_{0.5} \mathrm{Fe}_{0.5} \mathrm{Sn}$ [44] nanowires showing a $L 2_{1}$ crystal structure (with an $A 2$ and/or $B 2$ type disorder), which were synthesized by template-based ac electrodeposition; among other nanowire shape Heusler based alloys [45, 46].

Since $\mathrm{Co}_{2} \mathrm{FeIn}$ Heusler alloy was also predicted to exhibit a half-metallic nature [47], and it has also been earlier shown that the deposition of both Co-Fe and Co-In alloys from aqueous solutions is allowable $[48,49]$, we have synthetized Heusler-based $\mathrm{Co}_{2} \mathrm{Fe}$ In alloy nanowires via templateassisted electrochemical deposition in the pores of AAO membranes. This easy and low-cost fabrication method opens up to the new possibility in the synthesis of novel Heusler nanomaterials suitable for spintronic applications.

\section{Electrochemical synthesis and characterization of $\mathrm{Co}_{2} \mathrm{FeIn}$ alloyed nanowires in hard- anodic alumina templates}

The fabrication procedure here employed is based on the template-assisted pulsed electrodeposition method, as schematized in Figure S1 a) to S1 c), by employing highly ordered nanoporous AAO membranes obtained through hard anodization (HA) method in oxalic acid electrolyte, as previously reported elsewhere [50-52]. Additional details on the synthesis of $\mathrm{H}-$ $\mathrm{AAO}$ and their use as templates are given in the Supporting Information. 

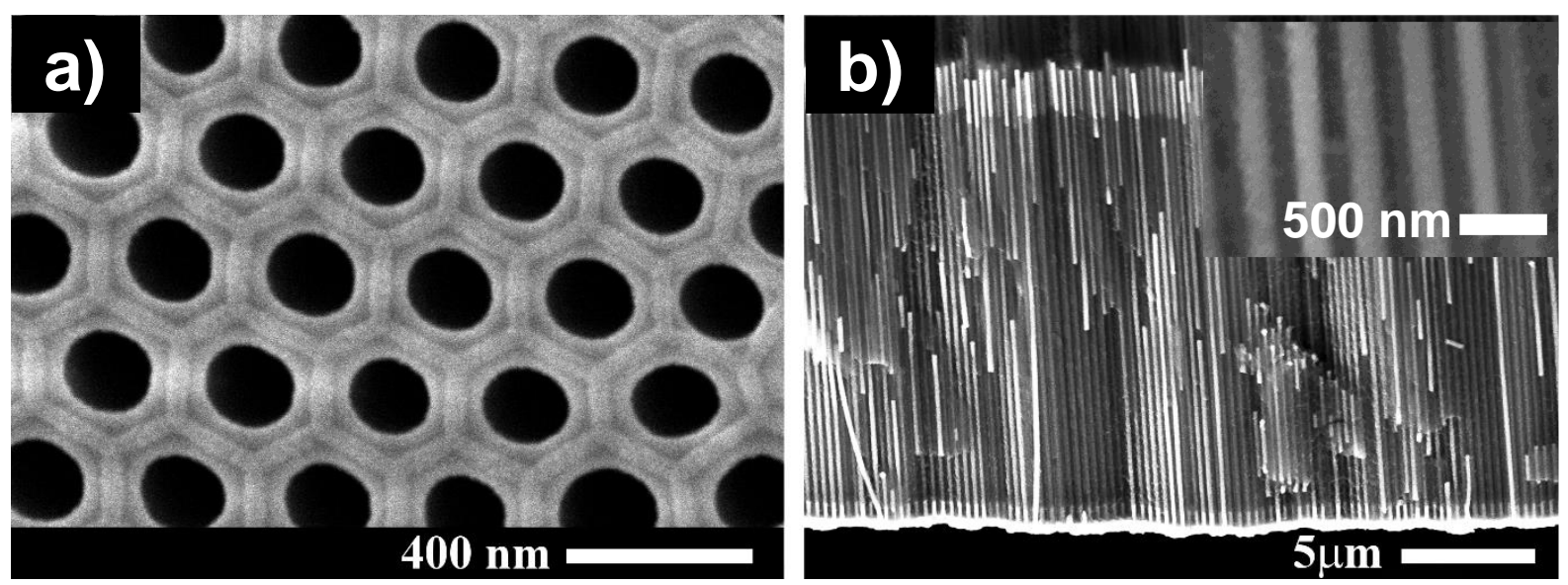

Figure 1: (a) SEM micrograph of the hexagonally self-ordered nanopores of the H-AAO membrane, which was employed afterwards as a template for DC deposition of $\mathrm{Co}_{2} \mathrm{FeIn}$ alloyed nanowires inside, and (b) the corresponding SEM cross-section image for the gold-capped $\mathrm{Co}_{2} \mathrm{FeIn}$ nanowires array. The inset shows a higher magnification of the SEM cross-section image of nanowires array.

In the scanning electron microscopy (SEM) top-view image of Figure 1 a), it is shown the hexagonally self-ordered nanoporous hard-anodic aluminum oxide (H-AAO) membrane, where a mean nanopore diameter of about $180 \mathrm{~nm}$ and interpores distance around $300 \mathrm{~nm}$ can be respectively measured.

\section{1 $\mathrm{SiO}_{2}$ cover layer by atomic layer deposition}

The prepared H-AAO membranes were coated by atomic layer deposition (ALD) technique with a protective $\mathrm{SiO}_{2}$ layer of $5 \mathrm{~nm}$ in thickness, as schematically depicted in Figures $\mathrm{S} 1 \mathrm{~b}$ ) and $1 \mathrm{c}$ ), to protect the further deposited metallic nanowires against corrosion and chemical etching [25, 27, 53]. The $\mathrm{SiO}_{2}$, cover layer was deposited into the pores of the H-AAO membranes by ALD working at $150^{\circ} \mathrm{C}$ from aminopropyltriethoxysilane $\left(100^{\circ} \mathrm{C}\right)$, water $(\mathrm{RT})$, and ozone $(\mathrm{RT})$, which 
were employed as precursors and oxidant agent, respectively [25-27, 53]. The ALD processes were performed in a Savannah 100 reactor (Cambridge Nanotech), employing long exposure times (45 s) of the H-AAO membranes to the ALD precursors, followed by extended purge steps (90 s). High Purity Ar (99.999\%), with a flow of $50 \mathrm{sccm}$ was employed as carrier and evacuation gas throughout the depositions.

\subsection{Electrodeposition of Co2FeIn alloyed nanowire arrays}

$\mathrm{Co}_{2} \mathrm{FeIn}$ alloyed nanowires were grown into the nanopores of $\mathrm{H}-\mathrm{AAO}$ membranes from aqueous electrolytes of $\mathrm{Co}, \mathrm{Fe}$ and In salts, as well as a mixture of additives comprising boric and ascorbic acids, sodium chloride, saccharin and gelatin, respectively. For the electrodeposition process of $\mathrm{Co}_{2} \mathrm{FeIn}$ alloy nanowires inside the pores of the H-AAO template, it consisted firstly of the backside coating of one side of the $\mathrm{SiO}_{2}$ functionalized $\mathrm{H}-\mathrm{AAO}$ membranes with a gold layer by means of sputtering (Polaron SC 7620), which served as working electrodes in further electrodeposition steps (see Figure $\mathrm{S} 1 \mathrm{~b}$ )). The potentiostatic Au electrodeposition made from a commercial gold plating solution (Orosene 999), gives rise to the growing of gold nanocontacts with length of about $2 \mu \mathrm{m}$, as shown in Figure 1b), Figure S1b), and Figure S3 a) of Supporting Info. After that, the $\mathrm{Co}_{2} \mathrm{FeIn}$ nanowires were electrochemically grown starting from an aqueous electrolytic bath containing: $0.198 \mathrm{M} \mathrm{CoCl}_{2}, 0.072 \mathrm{M} \mathrm{FeSO}_{4}, 0.023 \mathrm{M} \mathrm{In}_{2}\left(\mathrm{SO}_{4}\right)_{3}, 0.243 \mathrm{M} \mathrm{H}_{3} \mathrm{BO}_{3}$, 1.49 $\mathrm{M} \mathrm{NaCl}$, by adding a mixture of additives like ascorbic acid ( $5 \mathrm{mg} / \mathrm{l})$, gelatine $(2.5 \mathrm{mg} / \mathrm{l})$ and saccharin (5 mg/l). A galvanostatic pulsed electrodeposition (PED) approach was followed for the synthesis of $\mathrm{Co}_{2} \mathrm{Fe}$ In Heusler alloy nanowires, as indicated in Figure S2 of the Supporting Information. The PED process was carried out in a common two-electrode electrochemical cell made of Teflon, with Pt serving as the counter electrode and the gold-coated H-AAO template as the working electrode, and performed at room temperature (RT), with a deposition pulse of $12 \mathrm{~mA}$ 
for $1 \mathrm{~s}$ and a resting pulse at $0 \mathrm{~mA}$ (open circuit potential) for $1 \mathrm{~s}$. The number of deposition pulses was adjusted in order to grow the $\mathrm{Co}_{2}$ FeIn nanowires of about $15 \mu \mathrm{m}$ in length. Afterwards, gold caps about $1.6 \mu \mathrm{m}$ long were deposited in the upper part of the $\mathrm{Co}_{2} \mathrm{Fe}$ In nanowires, as a protection against corrosion in further chemical etching steps, as schematized in Figure S1 c), and can be clearly distinguished in the scanning electron micrograph of Figure $1 \mathrm{~b}$ ).

\subsection{Experimental characterization of $\mathrm{Co} 2 \mathrm{FeIn}$ alloy nanowires}

Linear sweep voltammetry (LSV) technique was used to obtain polarization curves (I-V), by employing a potentiostat-galvanostat Amel 7050 measured in a three-electrode configuration with an $\mathrm{Ag} / \mathrm{AgCl}$ reference electrode, and a $\mathrm{Pt}$ wire as the working electrode. The potentials were scanned in the range from 0.5 to $-2.0 \mathrm{~V}$, in negative direction, and afterwards reversed to the starting potential $(0.5 \mathrm{~V})$, at the three different sweeping rates of 20,50 and $100 \mathrm{mV} / \mathrm{s}$.

Structural characterization of the overall crystalline structure of $\mathrm{Co}_{2} \mathrm{FeIn}$ nanowire arrays grown in the H-AAO templates was determined by X-ray diffraction (XRD) analysis measured with a PANalytical X'Pert Pro MPD diffractometer employing $\mathrm{Cu} \mathrm{K} \alpha$ radiation $(\lambda=1.5418 \AA)$. The morphology and microstructure of the nanowires were respectively checked by using a scanning electron microscope (SEM), JEOL-6100 operated and $20 \mathrm{kV}$, and a transmission electron microscope (TEM), FEI-TITAN 80-300 kV operated at $300 \mathrm{kV}$. By employing the scanning transmission electron microscopy (STEM) mode, energy dispersive spectrometry (EDS) mapping images were obtained to take information on the distribution of chemical elements within individual nanowires. In order to perform the TEM analysis for the microstructural characterization of individual nanowires, they were released from the alumina membrane by chemical etching after dissolving it in a mixture of $\mathrm{H}_{3} \mathrm{PO}_{4}\left(6\right.$ wt.\%) and $\mathrm{CrO}_{3}\left(1.8\right.$ wt.\%) at $45^{\circ} \mathrm{C}$ 
for $48 \mathrm{~h}$. The $\mathrm{Co}_{2} \mathrm{Fe}$ In nanowires coated with $\mathrm{SiO}_{2}$ layer and covered with gold caps at both ends were then filtered and suspended in an absolute ethanol solvent. Subsequently, a small amount of nanowires was dispersed in ethanol-distilled water mixture (1:1) and sonicated for 30 min at RT. Finally, the released nanowires with the protective coating were dropped in a Lacey carbon grid, which was dried for 30 min under ambient environment for evaporating the solvent.

Thermomagnetic measurements and hysteresis loops (both, in parallel and perpendicular direction with respect to the nanowires axis), were measured in the arrays of nanowires by using a superconducting quantum interference device (SQUID), and Quantum Design magnetic property measurement system (MPMS) technique, within the temperature range from 10 to $400 \mathrm{~K}$, under applied magnetic fields up to $50 \mathrm{kOe}$.

The magnetic behavior of single nanowires was also measured by magneto-optical Kerr effect (MOKE) microscope in a NanoMOKE3 device (Durham Magneto-Optics) under applied AC fields of $500 \mathrm{Oe}$ at a frequency of $2.1 \mathrm{~Hz}$. For that purpose, the nanowires were dropped into monocrystalline Si wafers after releasing them from the nanoporous alumina template by wetchemical etching and suspended in ethanol, and then individually located by employing the laser scanning microscopy option of the NanoMOKE3. The single isolated $\mathrm{Co}_{2} \mathrm{FeIn}$ nanowires were carefully aligned with the direction of the applied magnetic field and measured employing longitudinal MOKE configuration. Averaging of up to 200 cycles was performed in order to improve the signal to noise ratio. Over 50 different nanowires were measured and the hysteresis loops were analyzed in order to extract the switching field distribution.

\section{Results and discussions}

\subsection{Cyclic voltammetry of electrodeposited Co2FeIn Heusler alloy}


The electrochemical features of the Co-Fe-In alloy electrodeposition behavior in the presence of additives were investigated by linear sweep voltammetry, LSV, by measuring the current-voltage (I-V) curves. Figure 2 shows the cathodic parts of cyclic voltammograms obtained for deposition of individual elements of $\mathrm{Co}, \mathrm{Fe}$, In and Co-Fe-In alloy on a Pt wire electrode, measured employing an $\mathrm{Ag} / \mathrm{AgCl}$ reference electrode. All electrolytes contained the same mixture of additives $(0.243$ $\mathrm{M} \mathrm{H}_{3} \mathrm{BO}_{3}, 1.49 \mathrm{M} \mathrm{NaCl}$, ascorbic acid, gelatine and saccharin). The cyclic voltammetry for a solution containing $0.198 \mathrm{M} \mathrm{CoCl}_{2}$ shows a single cathodic peak with the maximum at $-0.83 \mathrm{~V}$, which corresponds to the reduction of $\mathrm{Co}^{2+}$ into cobalt metal (see inset of Figure 2). This process was subsequently followed by the reduction of $\mathrm{H}^{+}$leading to $\mathrm{H}_{2}$ evolution, which is also present in the same range of voltage for the supporting electrolyte containing no metal salts (labelled as Additives in Figure 2).

The voltammetric curve for the aqueous solution containing $0.072 \mathrm{M} \mathrm{FeSO}_{4}$ indicates the reduction of $\mathrm{Fe}^{2+}$ by a broad peak starting at $-0.9 \mathrm{~V}$, which gradually passes to the hydrogen ion reduction reaction. Similarly, as in the case of Co the cyclic voltammetry curve corresponding to the deposition of In from the aqueous solution containing $0.023 \mathrm{M} \mathrm{In}_{2}\left(\mathrm{SO}_{4}\right)_{3}$ shows a well-defined anodic peak with the maximum at $-0.81 \mathrm{~V}$. Nevertheless, iron and indium could also be inductively codeposited with Co(II) ions, in both, simple salt or complexed aqueous electrochemical baths [48, 49, 54-55]. The initial abrupt current drop as the potential decreases is due to concentration depletion of metallic $\left(\mathrm{Fe}^{2+}, \mathrm{Co}^{2+}, \mathrm{In}^{3+}\right)$ ions near the electrode surface. Subsequently, the current slowly reaches a stable plateau. Noteworthy, for Co and In baths the diffusion-controlled mechanism reaches its limit current density at lower potential values than for the Co-Fe-In electrolyte. Therefore, the addition of Fe together with rest of additives causes essential changes in electrolyte solution, which ultimately might affect the characteristics of the reduction process. 


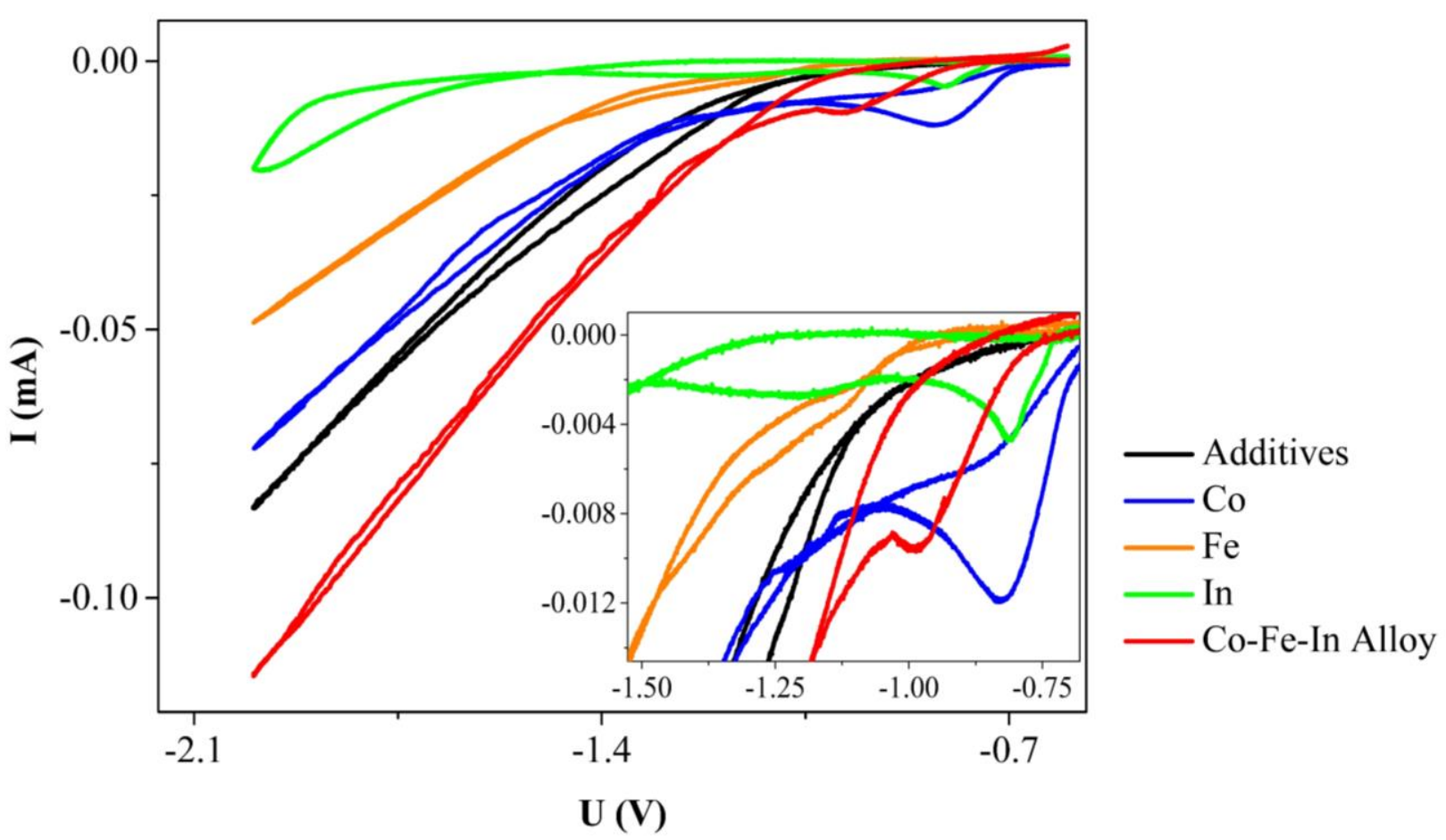

Figure 2: Cyclic voltammogram of the supporting electrolyte (labelled as additives), as well as the electrolytes containing individual elements (Co, Fe and In) and mixed Co-Fe-In electrolyte. The inset shows a detail of the potentials range at which appear the deposition peaks of Co, Fe and In, together with the corresponding one of the respective Co-Fe-In alloy.

In the case of the Co-Fe-In alloy, the electrodeposition starts at $-0.77 \mathrm{~V}$ and results in a single cathodic peak with maximum at $-0.98 \mathrm{~V}$. It is clear, that the co-deposition of the Co-Fe-In alloy takes place in the same range of voltage as for the deposition of individual elements. Therefore, this electrolyte is especially suitable for the electrochemical deposition of a ternary $\mathrm{Co}_{2} \mathrm{FeIn}$ Heusler alloy.

\subsection{Morphological, compositional and microstructural analysis of $\mathrm{Co}_{2} \mathrm{FeIn}$ nanowires}

Figure $1 \mathrm{~b}$ ) corresponds to a typical SEM cross-section view of the as-deposited densely packed array of $\mathrm{Co}_{2} \mathrm{FeIn}$ alloyed nanowires inside the pores of the H-AAO template. Additional bottom 
and top protective Au caps can also be well distinguished due to the back-scattered electrons (BSE) contrast. The resulting electroplated nanowire arrays have an averaged diameter of $180 \pm 20 \mathrm{~nm}$, around $300 \mathrm{~nm}$ of interspacing distance and $14.5 \mu \mathrm{m}$ in length, with a $\mathrm{Co}_{48} \mathrm{Fe}_{25} \mathrm{In}_{27}$ averaged composition obtained from EDS analysis with the SEM, (see Figure S3 from Supporting Info).

STEM mode images and EDS elemental mapping of the single isolated nanowires after releasing them from the nanoporous $\mathrm{H}-\mathrm{AAO}$ template have been taken in order to verify the shape and composition homogeneity of the $\mathrm{Co}_{2} \mathrm{Fe}$ In alloyed nanowires grown by pulsed electrodeposition, as they are shown in Figure 3.

These micrographs reveal that the $\mathrm{Co}, \mathrm{Fe}$ and In chemical content distributions are very uniform along the entire nanowires. The protective $\mathrm{SiO}_{2}$ coating layer that covers the $\mathrm{Co}_{2} \mathrm{FeIn}$ nanowires is rather uniform, as it can be clearly distinguished in the upper end of nanowire shown in the Figure 3 a). Local EDS analyses with TEM indicate an averaged percentage in atomic composition (at\%) of $\mathrm{Co}=47 \pm 1, \mathrm{Fe}=25 \pm 1, \mathrm{In}=28 \pm 1$, for the Co-Fe-In alloyed nanowires, in good agreement with the EDS analysis carried out by SEM. Individual $\mathrm{Co}_{2} \mathrm{FeIn}$ nanowires released from the hosting H-AAO membrane can be clearly distinguished form the low-magnification TEM image shown in the Figure S4 a) of Supporting Info, confirming the average nanowire diameter and length previously checked in the SEM images. 


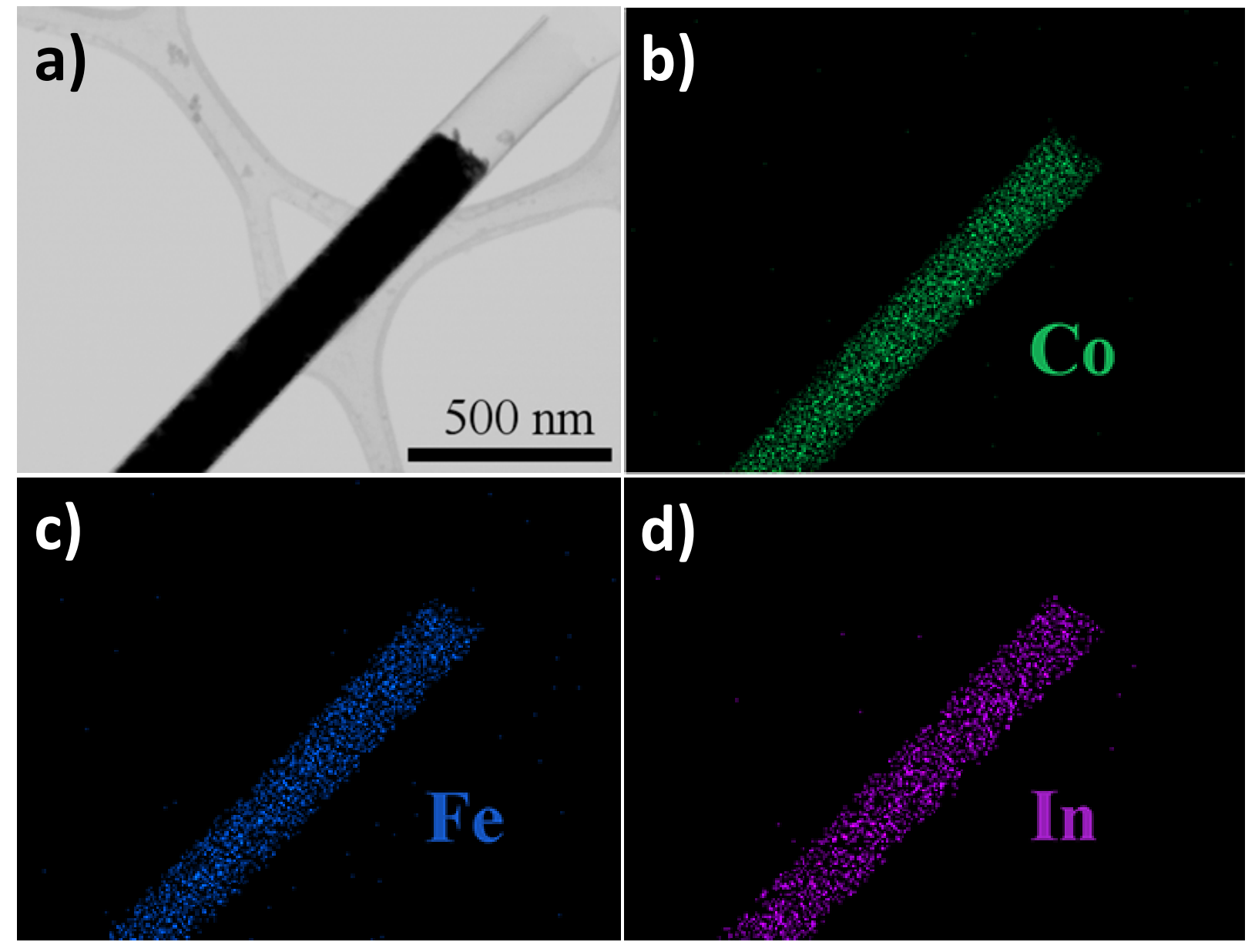

Figure 3: STEM image (a) and EDS elemental mapping analysis (b-d) of a single nanowire revealing that $\mathrm{Co}, \mathrm{Fe}$ and In elements are uniformly distributed throughout the whole nanowire dimension. The scale shown in (a) applies also to figures (b-d).

High-magnification TEM image shown in Figure S4 b) of Supporting Info, disclose the rather uniform conformal $\mathrm{SiO}_{2}$ coating layer deposited by $\mathrm{ALD}$ that covers the $\mathrm{Co}_{2} \mathrm{FeIn}$ alloyed nanowires, with a thickness of around $6 \mathrm{~nm}$.

Microstructural analysis of single isolated $\mathrm{Co}_{2} \mathrm{FeIn}$ Heusler nanowires was performed by highresolution transmission electron microscopy (HR-TEM) mode, as reported in Figure 4 a). The HRTEM images, combined with electron diffraction experiments shown in Figure $4 \mathrm{~b}$ ), reveal the 
polycrystalline features of electrodeposited nanowires. In the HR-TEM analysis shown in Figure 4 a), the polycrystalline structure of the nanowires is disclosed by direct observation of nanograins into the same nanowire. However, they tend to display the $\{220\}$ planes nearly oriented perpendicular to the nanowire long axis exhibiting a pronounced $\{220\}$ texture. The selected area electron diffraction, SAED, patterns (Figure $4 \mathrm{~b}$ ) show spotted rings that can be indexed to the reflections of the (220), (400), (422), (440), (620), (444), (642), (660), (840) and (862) planes of a $\mathrm{Co}_{2} \mathrm{FeIn}$ Heusler phase with a lattice parameter of $a=5.72 \pm 0.03 \AA$, which is lower than the calculated equilibrium lattice constant reported in reference [47]. All of such reflections satisfy the condition $\mathrm{h}+\mathrm{k}+\mathrm{l}=4 \mathrm{n}$ (where $\mathrm{n}$ is an integer) with $\mathrm{h}, \mathrm{k}$ and 1 all even. This fact is characteristic of a pure $A 2$ Heusler structure [38], within which the Co, Fe and In sites are disorderly distributed into the cubic crystalline structure of the $\mathrm{Co}_{2} \mathrm{FeIn}$ nanowires. For $B 2$ and $L 2_{1}$ structures, reflections satisfying the condition $\mathrm{h}+\mathrm{k}+\mathrm{l}=4 \mathrm{n}+2$ with $\mathrm{h}, \mathrm{k}, \mathrm{l}$ all even are also expected. Additionally, odd superlattice reflections (with $\mathrm{h}, \mathrm{k}$ and $\mathrm{l}$ all odd) is only expected for the $L 2_{1}$ structure [38].

XRD pattern of the $\mathrm{Co}_{2} \mathrm{FeIn}$ nanowires array shown in the Figure $4 \mathrm{c}$ ), confirmed the results obtained from the SAED analysis. Three well-defined peaks are observed at $44.4^{\circ}, 64.6^{\circ}$ and $81.8^{\circ}$, which can be indexed as the diffractions coming from the (220), (400) and (422) planes of a Heusler phase of the $\mathrm{Co}_{2}$ FeIn alloy with a lattice constant $a=5.764 \pm 0.001 \AA$. The coherence lengths obtained from these diffraction peaks using the Scherrer formula [56], (13, 11 and $10 \mathrm{~nm}$, respectively), are significantly smaller than the dimensions of the nanowires, indicating that nanowires are polycrystalline. On the other hand, the dominant (220) diffraction peak indicates that the $\mathrm{Co}_{2} \mathrm{FeIn}$ nanowires exhibit a crystalline texture with the [110] direction along the long axis of the nanowires, in agreement with the HR-TEM results. Moreover, a very small peak ascribed to the diffraction of the (111) planes corresponding to the fcc phase of metallic gold appears at 
$38.3^{\circ}$. The observed peaks of the $\mathrm{Co}_{2} \mathrm{FeIn}$ phase satisfy the condition $\mathrm{h}+\mathrm{k}+\mathrm{l}=4 \mathrm{n}$, (where $\mathrm{n}$ is an integer), characteristic for a pure $A 2$ Heusler structure, similarly as in the case of SAED pattern of a single nanowire [38].
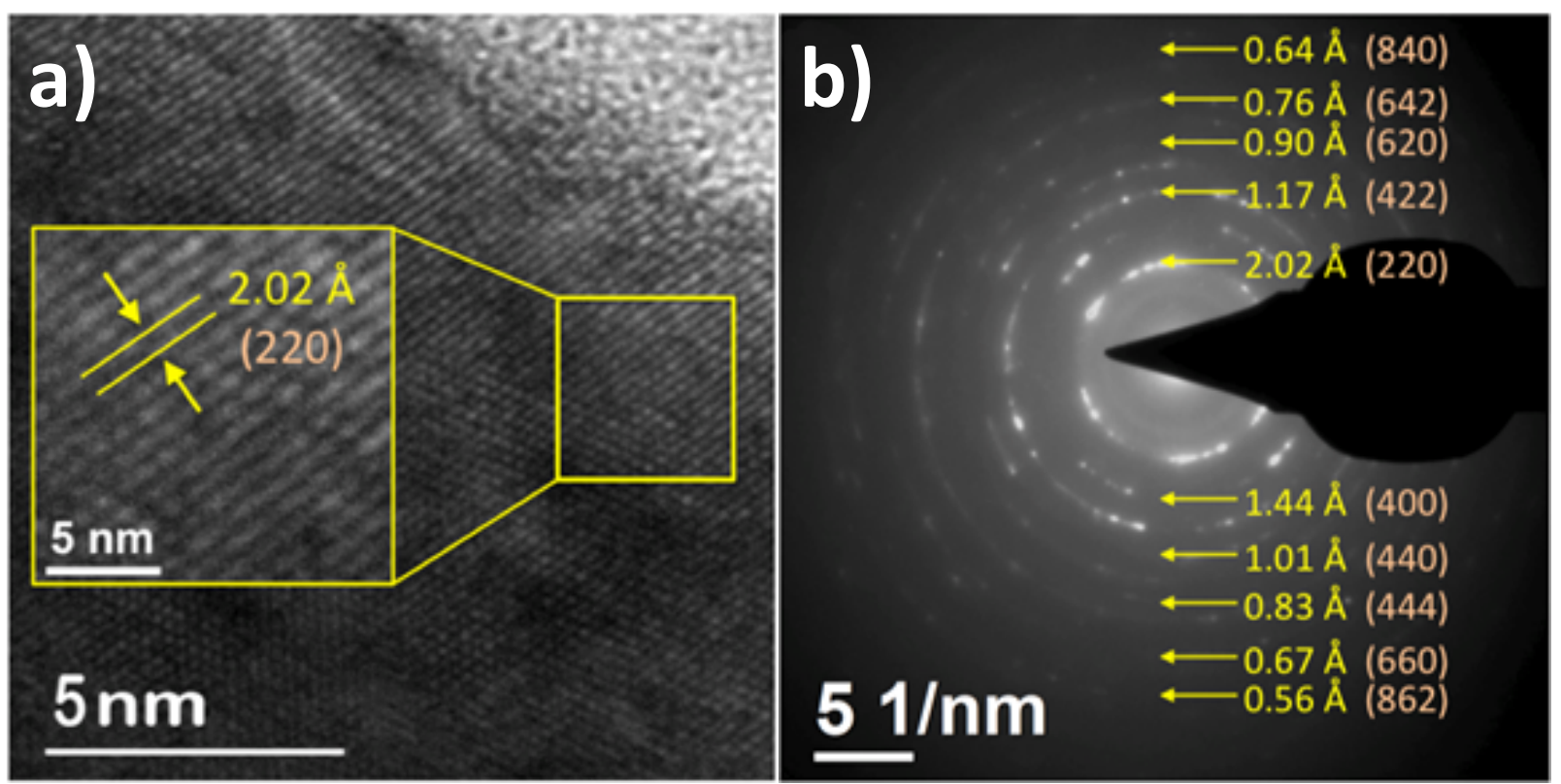

c)

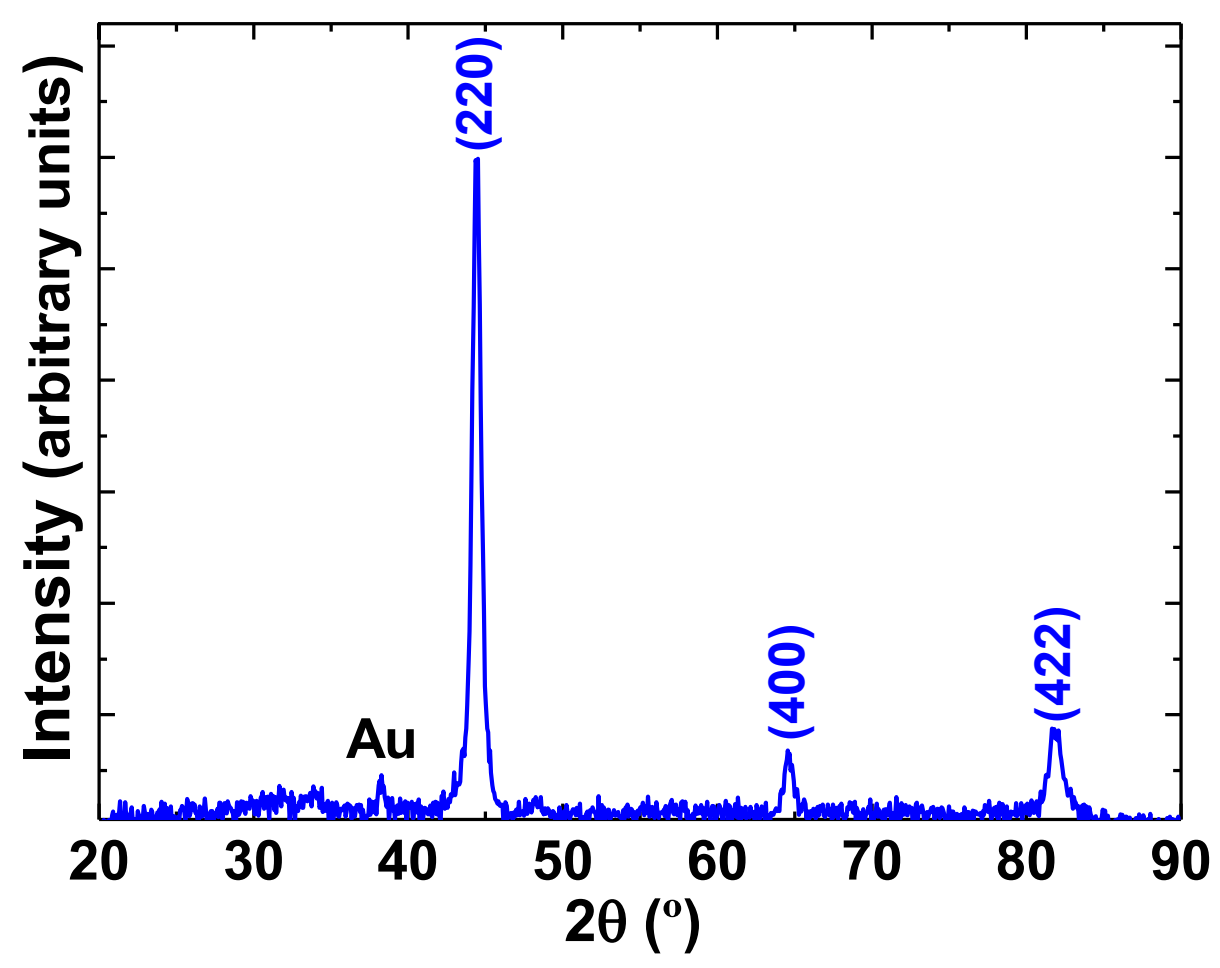

ACS Paragon Pliss Environment 
Figure 4: (a) HR-TEM micrograph of a single $\mathrm{Co}_{2} \mathrm{Fe}$ In alloy nanowire. The inset image is a magnification of the highlighted area. (b) SAED pattern of the single nanowire. (c) XRD spectrum of the $\mathrm{Co}_{2} \mathrm{FeIn}$ nanowires array embedded inside the pores of the $\mathrm{H}-\mathrm{AAO}$ template.

\subsection{Magnetic behavior of $\mathrm{Co}_{2} \mathrm{FeIn}$ nanowires}

In order to determine the whole magnetic behavior of the $\mathrm{Co}_{2} \mathrm{Fe}$ In Heusler alloy nanowires in the arrays, the magnetic hysteresis loops were measured in both, parallel and perpendicular directions of the applied magnetic field with respect to the nanowires axis, at the temperature of $10 \mathrm{~K}$ (Figure 5 a). The parallel and perpendicular hysteresis loops displayed in Figure 5 a, which are normalized by the maximum signal at saturation of the magnetization $\left(\mathrm{M}_{\mathrm{s}}\right)$, show a noticeable tilting towards increasing applied field values that is usually ascribed to the magnetostatic dipolar interactions among the nanowires in the array [26]. The squared shape of bulk magnetic hysteresis loop carried out in the parallel direction to the nanowires axis, points to the fact to a more bistable magnetic behavior whose easy magnetization axis lies parallel to the nanowire's longitudinal direction. Domain wall propagation dominates in this axial direction, as confirmed also by MOKE measurements carried out in single isolated nanowires.

The bulk hysteresis loops of the nanowire arrays measured in the perpendicular direction reveal that the magnetization rotation process becomes dominant along this hard magnetization axis. In this last direction, the magnetization begins to saturate at higher value of the applied magnetic field (7 kOe) in comparison to the hysteresis loop measured along the parallel direction ( $3 \mathrm{kOe})$. This fact indicates an anisotropic behavior where the easy magnetization axis may be close to the parallel direction to the nanowires axis. Coercive field $\left(\mathrm{H}_{\mathrm{C}}\right)$ of nanowires array for both applied magnetic field directions are also enhanced in the inset shown in the panel below. It can be clearly 
seen that coercivity measured at $10 \mathrm{~K}$ along the parallel direction to the nanowires axis reaches higher value ( $265 \mathrm{Oe})$, than in the perpendicularly magnetized direction $(\sim 1.5 \mathrm{Oe})$, what also indicates that the easy magnetization axis of the $\mathrm{Co}_{2} \mathrm{FeIn}$ alloy nanowires array lies along the nanowires length. This fact is due to the combined effects of the dominant role played by the magnetostatic shape anisotropy of the high aspect ratio (length/diameter) cylindrical nanowires, together with the crystalline texture along the [110] direction observed by XRD and HR-TEM in the polycrystalline nanowires. 

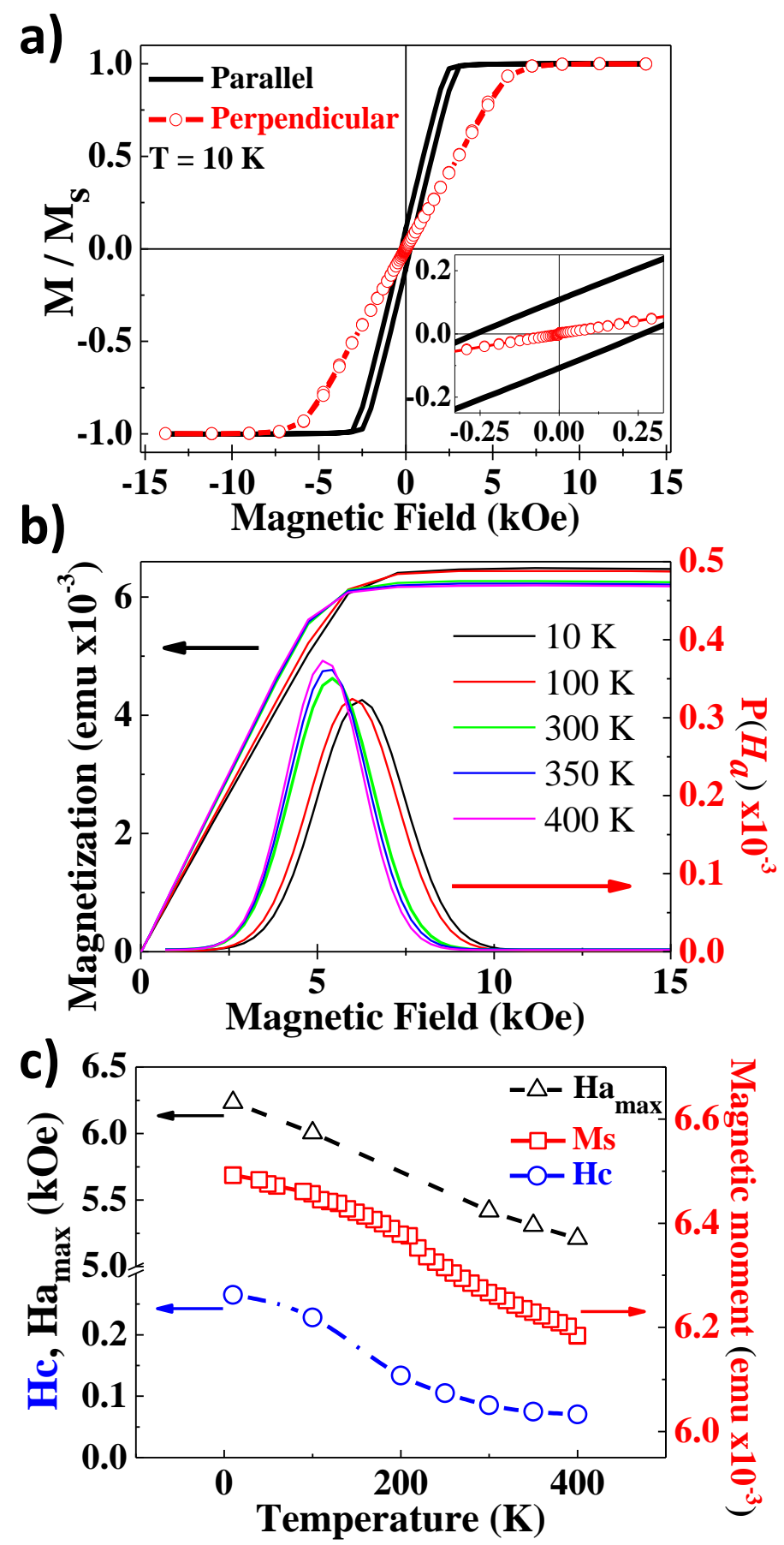

Figure 5: (a) Hysteresis loops of $\mathrm{Co}_{2} \mathrm{Fe}$ In Heusler alloy nanowires array embedded in $\mathrm{H}-\mathrm{AAO}$ template measured at $10 \mathrm{~K}$ along both, the parallel (line) and perpendicular (line with empty circles) direction of the applied magnetic field with respect to the nanowires axis. The inset displayed in the panel below shows a magnification of hysteresis loops at coercivity values. (b) Isothermal 
magnetization curves and corresponding anisotropy field distribution (AFD), obtained as a function of the temperature, for the $\mathrm{Co}_{2} \mathrm{Fe}$ In Heusler alloy nanowires perpendicularly magnetized to their longitudinal axis. (c) The comparison of temperature dependence of the maxima of the anisotropy field distribution $\left(\mathrm{Ha}_{\max }(\mathrm{T})\right)$, temperature dependence of saturation magnetization $\left(\mathrm{M}_{\mathrm{S}}(\mathrm{T})\right)$ measured under an external magnetic field of $10 \mathrm{kOe}$ and coercive field evolution with temperature $\left(\mathrm{H}_{\mathrm{C}}(\mathrm{T})\right.$ measured in the parallel direction to nanowires axis.

One of the crucial parameters that describes the magnetic properties of any magnetic system is its magnetic anisotropy, which is characterized by the anisotropy field, Ha. The anisotropy field distribution (AFD) can be easily determined from the magnetic hysteresis loops measured in the perpendicular direction with respect to the wires axis. Considering the magnetization curve of each nanowire, measured perpendicularly to the easy magnetization axis, which saturates at the anisotropy field value, Ha, the second order derivative of the magnetization curve gives the distribution of the anisotropy field $[57,58]$.

According to this method, the anisotropy field distribution, $\mathrm{P}(\mathrm{Ha})$, can be deducible from the positive descendent branch of the perpendicular hysteresis loop between saturation and remanence, detected in the perpendicular direction to the easy magnetization axis:

$$
P\left(H_{\mathrm{a}}\right)=-H \frac{d^{2}}{d H^{2}}<M(H)>\left.\right|_{H=H \mathrm{a}}
$$

where $\mathrm{M}$ is the magnetization and $\mathrm{H}$ is the applied field $[57,58]$.

Figure $5 \mathrm{~b}$ ) shows the isothermal magnetization curves and their corresponding anisotropy field distributions, $\mathrm{P}(\mathrm{Ha})$, obtained at different temperatures, for the $\mathrm{Co}_{2} \mathrm{FeIn}$ Heusler alloy nanowires when the magnetic field was applied perpendicularly to the nanowires length. The $\mathrm{P}(\mathrm{Ha})$ obtained 
from the hysteresis loop measured at $10 \mathrm{~K}$ shows a symmetric shape with a maximum at 6234 Oe and a full width at half maximum (FWHM) of 2468 Oe. With the increase of the temperature, the peak of the anisotropy distribution shifts to lower magnetic field value, which has been similarly observed in nanostructured systems [59]. The temperature dependence of the maximum of the $\mathrm{P}(\mathrm{Ha})$ distribution, together with the coercive field, $\mathrm{H}_{\mathrm{C}}$ (measured in the parallel direction), and saturation magnetization, $\mathrm{M}_{\mathrm{S}}$, are also plotted in Figure $5 \mathrm{c}$ ). The similar decrease observed for these three magnitudes $\left(\mathrm{P}(\mathrm{Ha}), \mathrm{H}_{\mathrm{C}}, \mathrm{M}_{\mathrm{S}}\right)$ with the temperature suggest the same origin, which can be explained in terms of the homogenization of the effective magnetic anisotropy. Small variations may be caused by the thermomagnetic evolution of the saturation magnetization. The origin for the temperature dependence of the effective magnetic anisotropy and coercivity should reflect the compromise of the temperature dependence for the overall magnetic anisotropy energy contributions namely, magnetoelastic, magnetocrystalline and shape or magnetostatic terms, where the most relevant role would be played by the magnetocrystalline and magnetoelastic anisotropy terms. In the last case, it has to be considered two contributions for the magnetoelastic coupling, the temperature dependence of the magnetostriction coefficient of the metallic alloy and that of the mechanical stress arising from the different thermal expansion coefficients between the metallic nanowires and the ceramic alumina template. On cooling, the metallic nanowires tend to contract faster than the ceramic alumina template, thereby giving rise to induced radial tensile mechanical stress, which result in an increasing of the uniaxial anisotropy parallel to the nanowires axis $[29,60]$.

Additionally, the temperature dependence of saturation magnetization, $\mathrm{M}_{\mathrm{S}}(\mathrm{T})$, of $\mathrm{Co}_{2} \mathrm{FeIn}$ Heusler nanowires shown in Figure 5 c), exhibits the ordinary ferromagnetic behavior. The Curie temperature $\left(\mathrm{T}_{\mathrm{C}}\right)$ was found to be well-above our experimental setup and room temperature, which 
is in a good agreement with the $\mathrm{T}_{\mathrm{C}}$ values of other $\mathrm{Co}_{2} \mathrm{Fe}$-based Heusler compounds $(\sim 1000 \mathrm{~K})$ [61].

On the other hand, there are some experimental works dealing with the magnetic properties of $\mathrm{Co}_{2} \mathrm{Fe}$-based Heusler alloys having similar compositions. Alloys in the form of bulk that were prepared by means of different experimental methods like electrochemical deposition $\left(\mathrm{Co}_{2} \mathrm{FeSn}\right)$ [62], arc melting ( $\left.\mathrm{Co}_{2} \mathrm{FeSi}\right)$ [63], and melt spinning ( $\left.\mathrm{Co}_{2} \mathrm{FeSi}\right)$ [64], exhibit a comparable soft ferromagnetic behavior with low $\mathrm{H}_{\mathrm{C}}$ values ranging up to $100 \mathrm{Oe}$.

In order to determine also the magnetic behavior of a single isolated $\mathrm{Co}_{2} \mathrm{FeIn}$ nanowire, magneto-optical Kerr effect (MOKE) technique has been used. The intrinsic magnetic behavior of single, isolated nanowires may be determined by measuring their hysteresis loops using the magneto-optical Kerr effect. This technique allows for characterizing isolated $\mathrm{Co}_{2} \mathrm{FeIn}$ nanowires without considering the effect of strong magnetostatic dipolar interaction that take place in densely packet nanowire arrays. In addition, hysteresis loop measurements performed by MOKE on single freestanding nanowires under different temperatures could provide an approached method for unveiling the different contributions to the magnetothermal behavior induced by magnetoelastic effects that appear in nanowire arrays embedded in AAO templates [60, 65], which could be subject of future works.

Figure 6 a) displays a representative example of the longitudinal MOKE hysteresis loops obtained for single isolated $\mathrm{Co}_{2} \mathrm{FeIn}$ alloy nanowires. The shape of the loops is similar to that previously reported in Co-rich nanowires [25], and it is characterized by a competition between shape and magnetocrystalline anisotropy contributions that lead to a complex magnetization reversal process. 

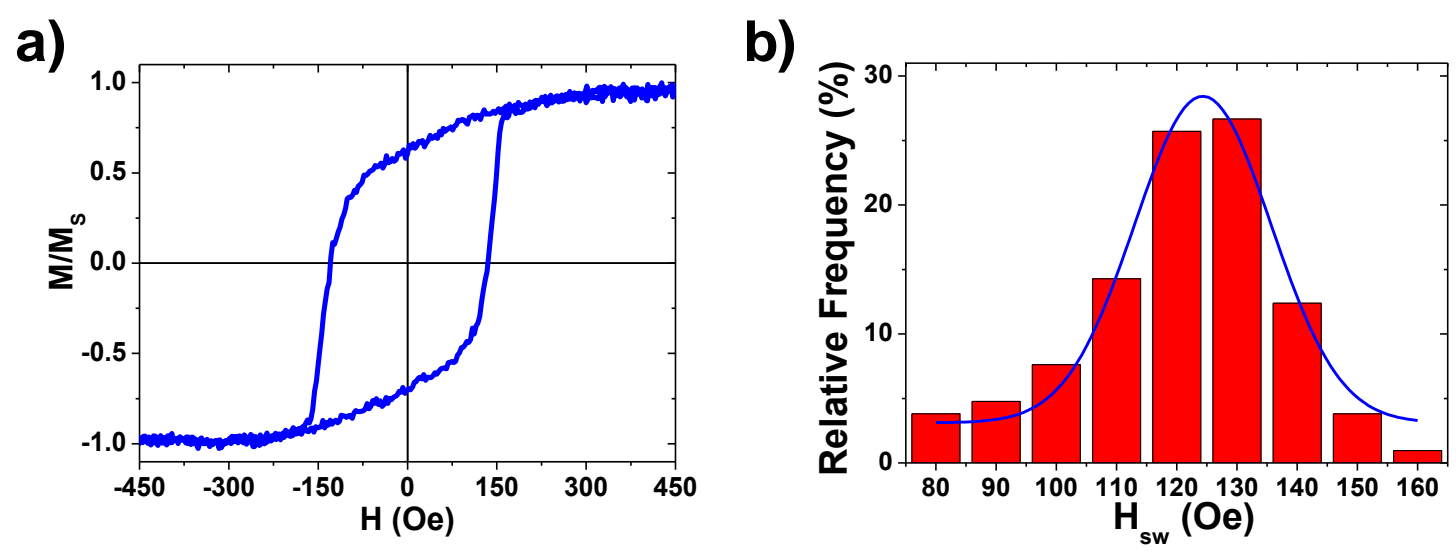

Figure 6: (a) Longitudinal MOKE hysteresis loops of a single $\mathrm{Co}_{2} \mathrm{FeIn}$ Heusler alloy nanowire measured at RT. (b) Switching field, $\mathrm{H}_{\mathrm{Sw}}$, distribution obtained from MOKE measurements for a population of over 50 single isolated $\mathrm{Co}_{2} \mathrm{Fe}$ In Heusler alloy nanowires.

In first place, the magnetization progressively decreases from saturation, suggesting local magnetization rotation processes as the applied magnetic field is reduced. Then, the magnetization of the nanowire switches in a single jump to the opposite value to that of the initial state. The switching field distribution $\left(\mathrm{H}_{\mathrm{Sw}}\right)$, was obtained from the measurement of about 50 independent nanowires, as shown in Figure 6 b). The dispersion in switching fields, Hsw, could be understood in terms of different factors, such as small variations in diameter and length between different nanowires. Nevertheless, a Gaussian-like distribution is found, with a mean value of $\left\langle\mathrm{H}_{\mathrm{Sw}}\right\rangle=124$ Oe and a FWHM of 27 Oe. The mean value of the switching field as measured by MOKE, $\left\langle\mathrm{H}_{\mathrm{SW}}\right\rangle$, is slightly larger than the coercivity, $\mathrm{H}_{\mathrm{C}}$, of the array of nanowires measured at the same temperature by SQUID, which takes a value of 85 Oe. This apparent discrepancy has been previously found in ferromagnetic nanowires and it is linked to the strong magnetostatic interactions that take place among neighboring nanowires in the array $[25,66]$.

\section{Conclusions}


In summary, we report on the first electrochemical synthesis of ternary $\mathrm{Co}_{2} \mathrm{FeIn}$ Heusler alloy nanowires, which are fabricated by a simple template-assisted electrodeposition method in H-AAO membranes. This template-based method of synthesis is a facile approach for obtaining large amounts (in the order of $10^{9}$ nanowires $/ \mathrm{cm}^{2}$ ) of dense metallic arrays of Heusler based nanowires with high aspect ratios, having a mean diameter of about $180 \mathrm{~nm}$ and around $14.5 \mu \mathrm{m}$ in length. The EDS elemental mapping analyses reveal that the chemical compositional distributions of the elements $(\mathrm{Co}, \mathrm{Fe}, \mathrm{In})$ is very uniform along the nanowires length. HR-TEM, SAED and XRD analyses confirmed that the $\mathrm{Co}_{2} \mathrm{Fe}$ In alloyed nanowires exhibit a polycrystalline character, having a cubic $A 2$ disordered Heusler structure with a lattice parameter of $5.764 \pm 0.001 \AA$ and (220) texture. Magnetic measurements, performed on both, nanowire arrays or single isolated and noninteracting nanowires, revealed their soft ferromagnetic behavior, where the magnetization rotation process dominate near saturation of magnetization and having the easy magnetization axis lying parallel aligned to the nanowires long axis, with the Curie temperature well-above the room temperature. As discussed before, the easy and low-cost preparation method of Heusler alloy nanowires via template-assisted electrochemical deposition is a promising and new forwardlooking fabrication of Heusler nanomaterials for their applications in many research fields such as in spintronics and magnetic data recording.

\section{Supporting Information.}

The supporting information is available free of charge, containing a detailed description of the fabrication of AAO templates by means of HA technique. In addition, current/voltage transients obtained during pulsed electrodeposition of $\mathrm{Co}_{2} \mathrm{FeIn}$ Heusler alloy nanowires are reported. SEM and TEM analysis of the $\mathrm{Co}_{2} \mathrm{FeIn}$ Heusler alloy nanowires, well in the array or after being released from the hosting pores of the alumina membrane, are also shown. 


\author{
AUTHOR INFORMATION \\ Corresponding Author \\ *Victor M. Prida. \\ Departamento de Física, Facultad de Ciencias, Universidad de Oviedo, C/ Federico Garcia Lorca \\ n 18 , 33007-Oviedo, Asturias (Spain). Telf.: +34-985103294, Fax: +34-985103324 e-mail: \\ vmpp@uniovi.es
}

\title{
Author Contributions
}

The manuscript was written through contributions of all authors. All authors have given approval to the final version of the manuscript.

\section{Funding Sources}

VEGA 1/0164/16, APVV-16-0079, VVGS-PF-2016-72614, MINECO MAT2013-48054-C2-2-R and MAT2016-76824-C3-3-R.

\section{ACKNOWLEDGMENT}

This work has been financially supported by VEGA 1/0164/16, APVV-16-0079, VVGS-PF-201672614, together Spanish MINECO research projects No MAT2013-48054-C2-2-R and MAT201676824-C3-3-R. The technical assistance provided by the Scientific-Technical Services (SCTs) of the University of Oviedo is also recognized. C. Luna thanks also to CONACYT for a sabbatical fellowship (ref. 215416). 


\section{REFERENCES}

[1] Felser, C.; Fecher, G. H.; Balke, B. Spintronics: A Challenge for Materials Science and Solid-State Chemistry Angew. Chem. Int. Ed. 2007, 46, 668-699.

[2] De Groot, R. A.; Müller, F. M.; Van Engen, P. G.; Buschow, K. H. J. New Class of Materials: Half-Metallic Ferromagnets Phys. Rev. Lett. 1983, 50, 2024-2027.

[3] Reiss, G.; Hutten, A. Magnetic Nanoparticles: Applications Beyond Data Storage Nat. Mater. 2005, 4, 725-726.

[4] Puydinger dos Santos, M. V.; Barth, S.; Béron, F.; Pirota, K. R.; Pinto, A. L.; Sinnecker, J. P.; Moshkalev, S.; Diniz, J. A.; Utke, I. Magnetoelectrical Transport Improvements of Postgrowth Annealed Iron-Cobalt Nanocomposites: A Possible Route for Future Room-Temperature Spintronics ACS Applied Nano Materials 2018, 1, 3364-3374.

[5] Klimczuk, T.; Wang, C. H.; Gofryk, K.; Ronning, F.; Winterlik, J.; Fecher, G. H.; Griveau, J.-C.; Colineau, E.; Felser, C.; Thompson, J. D.; Safarik, D. J.; Cava, R. J. Superconductivity in the Heusler Family of Intermetallics Phys. Rev. B 2012, 85, 174505.

[6] Ouardi, S.; Fecher, G. H.; Felser, C.; Kübler, J. Realization of Spin Gapless Semiconductors: The Heusler Compound $\mathrm{Mn}_{2} \mathrm{CoAl}$ Phys. Rev. Lett. 2013, 110, 100401.

[7] Sander, D.; Valenzuela, S. O.; Makarov, D.; Marrows, C. H.; Fullerton, E. E.; Fischer, P.; McCord, J.; Vavassori, P.; Mangin, S.; Pirro, P.; Hillebrands, B.; Kent, A. D.; Jungwirth, T.; Gutfleisch, O.; Kim, C. G.; Berger, A. The 2017 Magnetism Roadmap J. Phys. D: Appl. Phys. 2017, 50, 363001. 
[8] Graf, T.; Felser, C.; Parkin, S. S. P. Simple Rules for the Understanding of Heusler Compounds Prog. Solid State Chemistry 2011, 39, 1-50.

[9] Fecher, G. H.; Rausch, E.; Balke, B.; Weidenkaff, A.; Felser, C. Half-Heusler Materials as Model Systems for Phase-Separated Thermoelectrics Phys. Status Solidi A 2016, 213, 716-731.

[10] Serrate, D.; De Teresa, J. M.; Córdoba, R.; Yusuf, S. M. Magnetoresistance and Magnetostriction of $\mathrm{Co}_{2} \mathrm{Cr}_{0.6} \mathrm{Fe} 0.4 \mathrm{Al}$ Heusler Alloy Solid State Commun. 2007, 142, 363-367.

[11] Inomata, K.; Ikeda, N.; Tezuka, N.; Goto, R.; Sugimoto, S.; Wojcik, M.; Jedryka, E. Highly Spin-Polarized Materials and Devices for Spintronics Sci. Technol. Adv. Mater. 2008, 9, 014101.

[12] Wang, W.; Sukegawa, H.; Shan, R.; Mitani, S.; Inomata, K. Giant Tunneling Magnetoresistance Up to $330 \%$ at Room Temperature in Sputter Deposited $\mathrm{Co}_{2} \mathrm{FeAl} / \mathrm{MgO} / \mathrm{CoFe}$ Magnetic Tunnel Junction Appl. Phys. Lett. 2009, 95, 182502.

[13] Sakuraba, Y.; Ueda, M.; Miura, Y.; Sato, K.; Bosu, S.; Saito, K.; Shirai, M.; Konno, T. J.; Takanashi, K. Extensive Study of Giant Magnetoresistance Properties in Half-Metallic $\mathrm{Co}_{2}(\mathrm{Fe}, \mathrm{Mn}) \mathrm{Si}$-Based Devices Appl. Phys. Lett. 2012, 101, 252408.

[14] Obaida, M.; Galdun, L.; Ryba, T.; Komanicky, V.; Saksl, K.; Durisin, M.; Kovac, J.; Haskova, V.; Szabo, P.; Vargova, Z.; Varga, R. Spin Polarization in $\mathrm{Cu}_{2} \mathrm{MnSn}$ Heusler Alloy Produced by Melt-Spinning Intermetallics 2017, 85, 139-143.

[15] Pogorily, A. N.; Kravets, A. F.; Nevdacha, V. V.; Podyalovskiy, D. Y.; Ryabchenko, S. M.; Kalita, V. M.; Kulik, M. M.; Lozenko, A. F.; Vovk, A. Y.; Godinho, M.; Maurel, L.; Pardo, J. 
A.; Magen, C.; Korenivski, V. Magnetic Anisotropy of Epitaxial $\mathrm{Co}_{2} \mathrm{Fe}-\mathrm{Ge}$ Heusler Alloy Films on $\mathrm{MgO}$ (100) Substrates AIP Adv. 2017, 7, 055831.

[16] Sahoo, R.; Das, A.; Stuesser, N.; Suresh, K. G. Field Dependent Neutron Diffraction Study in $\mathrm{Ni}_{50} \mathrm{Mn}_{38} \mathrm{Sb}_{12}$ Heusler Alloy Appl. Phys. Lett. 2017, 110, 021902.

[17] Phatak, C.; Heinonen, O.; Graef, M. D.; Petford-Long, A. Nanoscale Skyrmions in a Nonchiral Metallic Multiferroic: Ni2MnGa Nano Lett. 2016, 16, 4141-4148.

[18] Liu, E. S.; Nah, J.; Varahramyan, K. M., Tutuc, E. Lateral Spin Injection in Germanium Nanowires Nano Lett. 2010, 10, 3297-3301.

[19] Lin, Y.-C.; Chen, Y.; Shailos, A.; Huang, Y. Detection of Spin Polarized Carrier in Silicon Nanowire with Single Crystal MnSi as Magnetic Contacts Nano Lett. 2010, 10, 2281-2287.

[20] Cortes-Huerto, R.; Ballone, P. Spontaneous Spin Polarization in Geometrically Constricted Metal Nanowires Phys. Rev. B 2009, 80, 233304.

[21] Niemann, A. C.; Böhnert, T.; Michel, A.-K.; Bäßler, S.; Gotsmann, B.; Neuróhr, K.; Tóth, B.; Péter, L.; Bakonyi, I.; Vega, V.; Prida, V. M.; Gooth, J.; Nielsch, K. Thermoelectric Power Factor Enhancement by Spin-Polarized Currents-A Nanowire Case Study Adv. Electron. Mater. 2016, 2, 1600058.

[22] Mehlin, A.; Xue, F.; Liang, D.; Du, H. F.; Stolt, M. J.; Jin, S.; Tian, M. L.; Poggio, M. Stabilized Skyrmion Phase Detected in MnSi Nanowires by Dynamic Cantilever Magnetometry Nano Lett. 2015, 15, 4839-4844. 
[23] Sagar, J.; Yu, C. N. T.; Lari, L.; Hirohata, A. Growth of Polycrystalline Heusler Alloys for Spintronic Devices J. Phys. D: Appl. Phys. 2014, 47, 265002.

[24] Carrete, J.; Mingo, N.; Wang, S.; Curtarolo, S. Nanograined Half-Heusler Semiconductors as Advanced Thermoelectrics: An Ab Initio High-Throughput Statistical Study Adv. Funct. Mater. 2014, 24, 7427-7432.

[25] Vega, V.; Böhnert, T.; Martens, S.; Waleczek, M.; Montero-Moreno, J. M.; Görlitz, D.; Prida, V. M.; Nielsch, K. Tuning the Magnetic Anisotropy of Co-Ni Nanowires: Comparison Between Single Nanowires and Nanowire Arrays in Hard-Anodic Aluminum Oxide Membranes Nanotechnology 2012, 23, 465709.

[26] García, J.; Vega, V.; Iglesias, L.; Prida, V. M.; Hernando, B.; Barriga-Castro, E. D.; Mendoza-Reséndez, R.; Luna, C.; Görlitz, D.; Nielsch, K. Template-Assisted Co-Ni Alloys and Multisegmented Nanowires with Tuned Magnetic Anisotropy Phys. Status Solidi A 2014, 211, 1041-1047.

[27] Méndez, M.; González, S.; Vega, V.; Teixeira, J. M.; Hernando, B.; Luna, C.; Prida, V. M. Ni-Co Alloy and Multisegmented Ni/Co Nanowire Arrays Modulated in Composition: Structural Characterization and Magnetic Properties Crystals 2017, 7, 66.

[28] Maqableh, M. M.; Huang, X.; Sung, S.-Y.; Madhukar Reddy, K. S.; Norby, G.; Victora, R. H.; Stadler, B. J. H. Low-Resistivity 10 nm Diameter Magnetic Sensors Nano Lett. 2012, 12, 4102-4109.

[29] Garcia, J.; Prida, V. M.; Vivas, L. G.; Hernando, B.; Barriga-Castro, E. D.; MendozaReséndez, R.; Luna, C.; Escrig, J.; Vázquez, M. Magnetization Reversal Dependence on Effective 
Magnetic Anisotropy in Electroplated Co-Cu Nanowire Arrays J. Mater. Chem. C 2015, 3, 46884697.

[30] Fu, P.; Chen, G.; Xu, Y.; Cai, P.; Wang, X. H. Electrodeposition and Magnetic Properties of Ternary Fe-Co-Ni Alloy Nanowire Arrays With High Squareness Ratio Mater. Sci.-Poland 2012, 30, 259-263.

[31] Rodríguez, L. A.; Bran, C.; Reyes, D.; Berganza, E.; Vázquez, M.; Gatel, C.; Snoeck, E.; Asenjo, A. Quantitative Nanoscale Magnetic Study of Isolated Diameter-Modulated FeCoCu Nanowires ACS Nano 2016, 10, 9669-9678.

[32] Piraux, L.; Renard, K.; Guillemet, R.; Mátéfi-Tempfli, S.; Mátéfi-Tempfli, M.; Antohe, V. A.; Fusil, S.; Bouzehouane, K.; Cros, V. Template-Grown NiFe/Cu/NiFe Nanowires for Spin Transfer Devices Nano Lett. 2007, 7, 2563-2567.

[33] Haehnel, V.; Mickel, C.; Fähler, S.; Schultz, L.; Schlörb, H. Structure, Microstructure, and Magnetism of Electrodeposited $\mathrm{Fe}_{70} \mathrm{Pd}_{30}$ Nanowires J. Phys. Chem. C 2010, 114, 19278-19283.

[34] Taggart, D. K.; Yang, Y.; Kung, S.-C.; McIntire, T. M.; Penner, R. M. Enhanced Thermoelectric Metrics in Ultra-long Electrodeposited PEDOT Nanowires Nano Lett. 2011, 11, $125-131$.

[35] Barriga-Castro, E. D.; García, J.; Mendoza-Reséndez, R.; Prida, V. M.; Luna, C. PseudoMonocrystalline Properties of Cylindrical Nanowires Confinedly Grown by Electrodeposition in Nanoporous Alumina Templates RSC Advances 2017, 7, 13817-13826. 
[36] Hirohata, A.; Kuchi, M.; Tezuka, N.; Inomata, K.; Claydon, J. S.; Xu, Y. B.; Van der Laan, G. Heusler Alloy/Semiconductor Hybrid Structures Curr. Opin. Solid. Stat. Mater. 2006, 10, $93-$ 107.

[37] Tsai, C.-I; Wang, C.-Y.; Tang, J.; Hung, M.-H.; Wang, K. L.; Chen, L.-J. Electrical Properties and Magnetic Response of Cobalt Germanosilicide Nanowires ACS Nano 2011, 5, 9552-9558.

[38] Sapkota, K. R.; Gyawali, P.; Forbes, A.; Pegg, I. L.; Philip, J. Synthesis and Characterization of $\mathrm{Co}_{2} \mathrm{FeAl}$ Nanowires J. Appl. Phys. 2012, 111, 123906.

[39] Li, W.-J.; Khan, U.; Irfan, M.; Javed, K.; Liu, P.; Ban, S.L.; Han, X.F. Fabrication and Magnetic Investigations of Highly Uniform CoNiGa Alloy Nanowires J. Magn. Magn. Mater. 2017, 432, 124-128.

[40] Hu, S.; Itoh, H.; Kimura, T. Efficient Thermal Spin Injection Using CoFeAl Nanowire NPG Asia Materials 2014, 6, e127.

[41] Simon, P.; Wolf, D.; Wang, Ch.; Levin, A. A.; Lubk, A.; Sturm, S.; Lichte, H.; Fecher, G.; Felser, C. Synthesis and Three-Dimensional Magnetic Field Mapping of $\mathrm{Co}_{2} \mathrm{FeGa}$ Heusler Nanowires at $5 \mathrm{~nm}$ Resolution Nano Lett. 2016, 16, 144-120.

[42] Li, X.; Lv, H.; Dai, J.; Ma, L.; Zeng, X. C.; Wu, X.; Yang, J. Half-Metallicity in OneDimensional Metal Trihydride Molecular Nanowires J. Am. Chem. Soc. 2017, 139, 6290-6293. 
[43] Khan, S.; Ahmad, N.; Ahmed, N.; Safeer, A.; Iqbal, J.; Han, X. F. Structural, Magnetic and Transport Properties of Fe-Based Full Heusler Alloy $\mathrm{Fe}_{2} \mathrm{CoSn}$ Nanowires Prepared by TemplateBased Electrodeposition J. Magn. Magn. Mater. 2018, 465, 462-470.

[44] Khan, S.; Ahmed, N.; Ahmad, N.; Han, X. F. Analysis of Electronic, Magnetic and HalfMetallic Properties of $L 2{ }_{1}$-Type $\left(\mathrm{Co}_{2} \mathrm{Mn}_{0.5} \mathrm{Fe}_{0.5} \mathrm{Sn}\right)$ Heusler Alloy Nanowires Synthesized by ACElectrodeposition in AAO Templates J. Magn. Magn. Mater. 2018, 460, 120-127.

[45] Seo, K.; Bagkar, N.; Kim, S.-in; In, J.; Yoon, H.; Jo, Y.; Kim, B. Diffusion-Driven Crystal Structure Transformation: Synthesis of Heusler Alloy Fe 3 Si Nanowires Nano Lett. 2010, 10, 36433647.

[46] Hilse, M.; Herfort, J.; Jenichen, B.; Trampert, A.; Hanke, M.; Schaaf, P.; Geelhaar, L.; Riechert, H. GaAs-Fe 3 Si Core-Shell Nanowires: Nanobar Magnets Nano Lett. 2013, 13, 62036206.

[47] El Amine Monir, M.; Khenata, R.; Baltache, H.; Murtaza, G.; Abu-Jafar, M. S.; Bouhemadou, A.; Omran, S. B.; Rached, D. Study of Structural, Electronic and Magnetic Properties of CoFeIn And $\mathrm{Co}_{2}$ FeIn Heusler Alloys J. Magn. Magn. Mater. 2015, 394, 404-409.

[48] Bran, C.; Palmero, E. M.; Li, Z.-A.; Del Real, R. P.; Spasova, M.; Farle, M.; Vázquez, M. Correlation Between Structure and Magnetic Properties in $\mathrm{Co}_{\mathrm{x}} \mathrm{Fe}_{100-\mathrm{x}}$ Nanowires: The Roles of Composition and Wire Diameter J. Phys. D: Appl. Phys. 2015, 48, 145304.

[49] Krastev, I.; Dobrovolska, Ts.; Lačnjevac, U.; Nineva, S. Pattern Formation During Electrodeposition of Indium-Cobalt Alloys J. Solid State Electr. 2012, 16, 3449-3456. 
[50] V. M. Prida, V. Vega, J. García, L. Iglesias, B. Hernando, I. Mínguez-Bacho; I. Electrochemical methods for template-assisted synthesis of nanostructured materials, in Magnetic Nano- and Microwires; Woodhead Publishing Series in Electronic and Optical Materials; M. Vázquez (Ed.), 2015, pp. 1-39. ISBN 978-0-08-100164-6.

[51] Lee, W.; Ji, R.; Gösele, U.; Nielsch, K. Fast Fabrication of Long-Range Ordered Porous Alumina Membranes by Hard Anodization Nat. Mater. 2006, 5, 741-747.

[52] Vega, V.; García, J.; Montero-Moreno, J. M.; Hernando, B.; Bachmann, J.; Prida, V. M.; Nielsch, K. Unveiling the Hard Anodization Regime of Aluminum: Insight into Nanopores SelfOrganization and Growth Mechanism ACS App. Mater. Interfaces 2015, 7, 28682-28692.

[53] Bachmann, J.; Zierold, R.; Chong, Y. T.; Hauert, R.; Sturm, C.; Schmidt-Grund, R.; Rheinländer, B.; Grundmann, M.; Gösele, U.; Nielsch, K. A Practical, Self-Catalytic, Atomic Layer Deposition of Silicon Dioxide Angew. Chem. Int. Ed. 2008, 47, 6177-6179.

[54] Lallemand, F.; Ricq, L.; Deschaseaux, E.; De Vettor, L.; Berçot, P. Electrodeposition of Cobalt-Iron Alloys in Pulsed Current from Electrolytes Containing Organic Additives Surf. Coat. Technol. 2005, 197, 10-17.

[55] Sadana, Y. N.; Keskinen, A. E.; Guindon, M. Electrodeposition of Alloys III. Electrodeposition and X-Ray Structure of Cobalt-Indium Alloys (Initial Studies) Electrodeposition Surf. Treat. 1975, 3, 149-157.

[56] Cullity, B. D.; Stock, S. R. Elements of X-Ray Diffraction, 3rd Ed., Prentice-Hall Inc., 2001, pp. 167-171, ISBN 0-201-61091-4 
[57] Barandiaran, J. M.; Vázquez, M.; Hernando, A.; Gonzalez, J.; Rivero, G. Distribution of the Magnetic Anisotropy in Amorphous Alloys Ribbons IEEE Trans. Mag. 1989, 25, 3330-3332.

[58] Bottoni, G.; Candolfo, D.; Cechetti, A. Distribution of Anisotropy Field in Recording Media Deduced from the Hysteresis Curve J. Appl. Phys. 1998, 81, 3794-3796.

[59] Franco, V.; Pirota, K. R.; Prida, V. M.; Neto, A. M. J.; Conde, A.; Knobel, M.; Hernando, B.; Vazquez, M. Tailoring of Magnetocaloric Response in Nanostructured Materials: Role of Anisotropy Phys. Rev. B 2008, 77, 104434.

[60] Navas, D.; Pirota, K.R.; Mendoza-Zelis, P.; Velazquez, D.; Ross, C. A.; Vazquez, M. Effects of the Magnetoelastic Anisotropy in Ni Nanowire Arrays J. Appl. Phys. 2008, 103, $07 \mathrm{D} 523$.

[61] Wurmehl, S.; Fecher, G. H.; Kandpal, H. Ch.; Ksenofontov, V.; Felser, C. Investigation of $\mathrm{Co}_{2} \mathrm{FeSi}$ : The Heusler Compound with Highest Curie Temperature and Magnetic Moment Appl. Phys. Lett. 2006, 88, 032503.

[62] Duan, J.; Kou, X. J. Effect of Current Density on the Microstructure and Magnetic Properties of Electrodeposited $\mathrm{Co}_{2}$ FeSn Heusler Alloy Electrochem. Soc. 2013, 160, D471-D475.

[63] Titov, A.; Zivotsky, O.; Hendrych, A.; Janickovic, D.; Bursik, J.; Jiraskova, Y. $\mathrm{Co}_{2} \mathrm{FeSi}$ Heusler Alloy Prepared by Arc Melting and Planar Flow Casting Methods: Microstructure and Magnetism Acta Phys. Pol. A 2017, 131, 654-656. 
[64] Galdun, L.; Ryba, T.; Kováč, J.; Prida, V. M.; Hernando, B.; Vargová, Z.; Varga R. Influence of Mn Doping on Magnetic and Structural Properties of $\mathrm{Co}_{2} \mathrm{FeSi}$ Heusler Alloy Acta Phys. Pol. A 2017, 131, 866-868.

[65] Pirota, K. R.; Silva, E. L.; Zanchet, D.; Navas, D.; Vázquez, M.; Hernández-Vélez, M.; Knobel M. Size Effect and Surface Tension Measurements in Ni and Co Nanowires Phys. Rev. B 2007, 76, 233410.

[66] Sergelius, P.; Garcia Fernandez, J.; Martens, S.; Zocher, M.; Böhnert, T.; Vega Martinez, V.; de la Prida, V.M.; Görlitz, D.; Nielsch, K. Statistical Magnetometry on Isolated NiCo Nanowires and Nanowire Arrays: A Comparative Study J. Phys. D: Appl. Phys. 2016, 49, 145005. 
Table of Content (TOC)

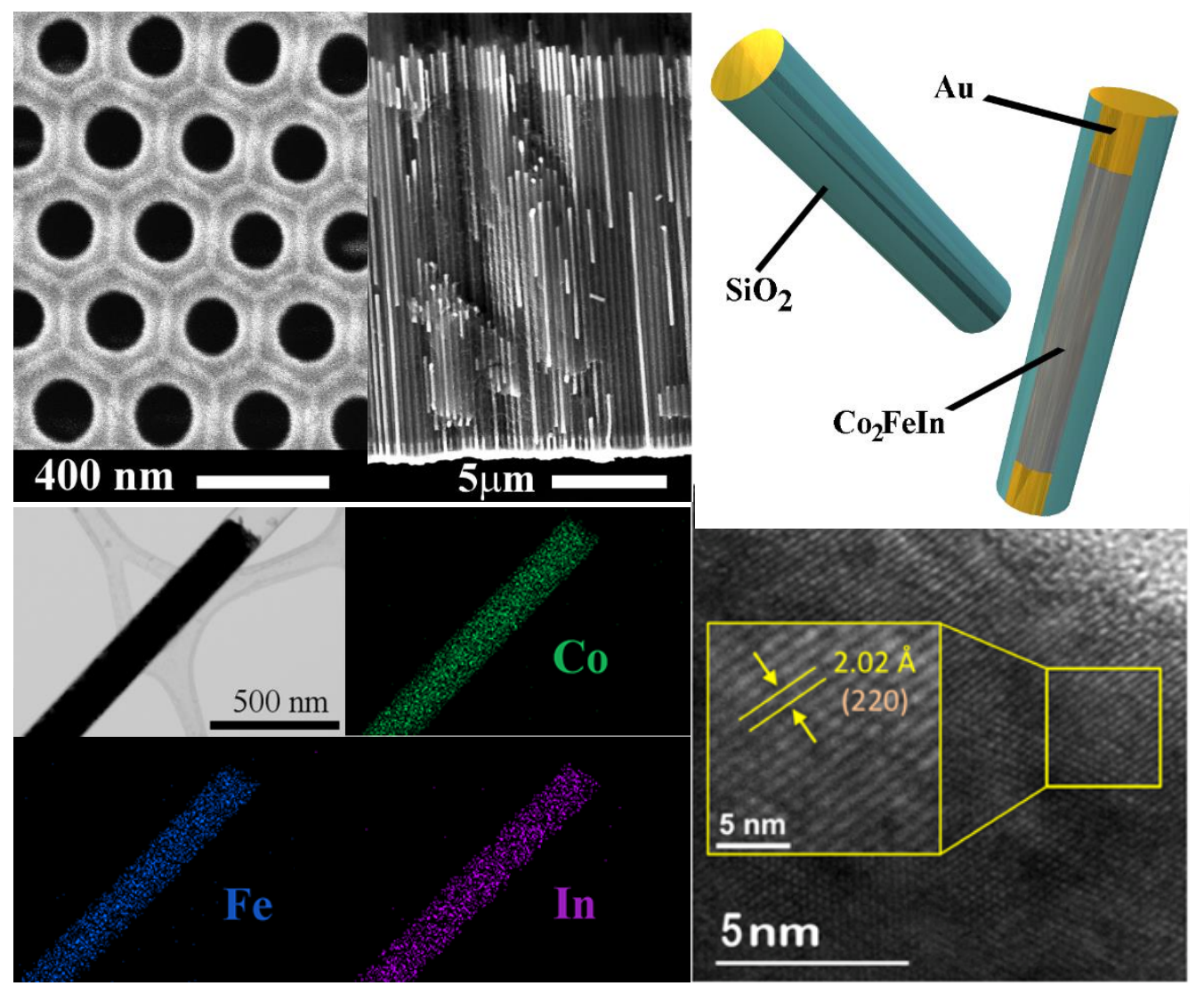

